\title{
DESIGNING A RATIONAL DISTRIBUTION NETWORK FOR TRADING COMPANIES
}

\author{
V.V. Dybskaya ${ }^{1}$, P.A. Sverchkov ${ }^{2}$ \\ ${ }^{I}$ National Research University Higher School of Economics, \\ Moscow, Russia, Office 301, building 3, Bolshoi Trekhsvyatitelskiy pereulok \\ +7 (495) 772-95-90,vdybskaya@hse.ru \\ ${ }^{2}$ National Research University Higher School of Economics, \\ Moscow, Russia, Office 320, building 3, Bolshoi Trekhsvyatitelskiy pereulok \\ +7(495) 772-95-90, sverchkov87@mail.ru
}

This article considers the modern methods and approaches to design the company's distribution network. The authors point out the relevance of this problem for the modern trading and manufacturing companies, give examples of the strategic goal setting of the company in the logistics network reorganization, and the benchmarks of possible economic effects of its conduction. The work reviews the scientific articles of contemporary American, European and Russian authors devoted to the approaches, concerning the implementation of projects for designing a distribution network, methods and models for its optimization. The article concludes that there is no single "language" and an approach to design the logistics networks, with a proper level of detail that takes into account the strategic features and industry specificity of the certain company. The authors propose an algorithm for designing a rational distribution network.

Keywords: network design, network optimization, distribution network, retail trade, logistic strategy

\section{Introduction}

The development of an efficient distribution network for finished products is one of the basic tasks facing the logistics departments in the large manufacturing and trading enterprises. The strategic nature of this problem and its special relevance in the modern conditions, are determined by the following factors:

- configuration of the distribution network (primarily, volume and location of the logistics capacity) determines the long-term efficiency of the company's logistic activities in terms of the transportation and storage costs level, as well the achievable indicators of logistics service;

- activity scale of the modern Russian enterprises (in particular, the retail network and wholesale trade companies) involves servicing the thousands of consumers (stores) in the dozens of country regions located several thousand kilometres apart (see Table 1), which creates the significant challenges in the field of distribution logistics;

- a significant reduction in rental rates and purchase of the storage capacity in Russia (2-fold in the US dollar terms and by $20 \%$ - in rubles) under the influence of changes in exchange rates and increasing level of the competition pose the unprecedented conditions for expanding their own logistical capacities, thus creating a sustainable competitive advantage.

Table 1. Information on the scale of logistics operations of the leading retail network companies

\begin{tabular}{|l|l|l|l|l|l|l|}
\hline Retail company & $\begin{array}{l}\text { Rating } \\
\text { position, } \\
\mathbf{2 0 1 6}\end{array}$ & $\begin{array}{l}\text { Number } \\
\text { of stores } \\
\text { managed }\end{array}$ & $\begin{array}{l}\text { Number of the } \\
\text { settlements }\end{array}$ & $\begin{array}{l}\text { Number } \\
\text { of the DCs }\end{array}$ & $\begin{array}{l}\text { Number of the } \\
\text { RCs opened in } \\
\mathbf{2 0 1 5 - 2 0 1 6}\end{array}$ & $\begin{array}{l}\text { Number } \\
\text { of vehicles } \\
\text { (own fleet) }\end{array}$ \\
\hline "Magnit" & 1 & 12,434 & 2,397 & 34 & 7 & $\sim 6,000$ \\
\hline "X5 Retail Group" & 2 & 8,574 & 950 & 35 & 8 & 1,560 \\
\hline "Dixie" & 3 & 2,758 & 774 & 8 & 3 & 660 \\
\hline "Lenta" & 4 & 170 & 72 & 7 & 1 & $\sim 80$ \\
\hline "Okay" & 5 & 158 & 28 & 8 & 1 & n/a \\
\hline
\end{tabular}

The problem of distribution network designing (forming) becomes relevant for the certain company in two cases:

- when the developed logistical strategy, reflecting the goals and objectives of corporate strategy, affects the efficiency of logistics infrastructure; 
- when the organization is influenced by the internal or external factors, causing some changes in the competitive landscape or other significant business operating conditions.

The logistics network design may also be initiated by the logistic activities themselves, for example, because of changes in the key performance indicators of the current distribution network identified during the analysis. In this case, generally, we are talking about the distribution network reorganization.

The results of Russian companies' projects for the distribution network reorganization ("Baltika", "Eldorado", "Leroy Merlin", "PepsiCo" (the Russian subdivision), "VimpelCom", and others) show that the potential for reducing the overall logistics costs by its implementation varies from $5 \%$ to $15 \%$, depending on the industry specific nature and the limits of possible changes. At the same time, the logistics costs minimization does not always mean the only possible goal of such projects, since often the corporate strategy pursues other priorities, which are expressed in improving the quality or terms of the company's customer service (see Table 2).

Table 2. Strategic objectives of the logistic activities in designing the distribution network

\begin{tabular}{|c|c|c|}
\hline $\begin{array}{l}\text { Strategic objective } \\
\text { of the logistic activities }\end{array}$ & Description & Example \\
\hline Providing the service flexibility & $\begin{array}{l}\text { Maintaining readiness for the rapid changes in the scope of supplies, incl. } \\
\text { taking into account the geographically distributed sales structure }\end{array}$ & "Adidas" \\
\hline Increasing the response rate & $\begin{array}{l}\text { Ensuring the shortest time to meet the urgent needs of customers, the } \\
\text { fastest delivery }\end{array}$ & "Zara" \\
\hline Ensuring the stocks availability & $\begin{array}{l}\text { Maintaining an optimum level of commodity stocks, sufficient for } \\
\text { providing the deficit-free operation }\end{array}$ & $\begin{array}{l}\text { "METRO } \\
\text { Cash \& Carry" }\end{array}$ \\
\hline Improving the service quality & $\begin{array}{l}\text { Ensuring a high level of customer service, return flows service, meeting } \\
\text { the repair deadlines }\end{array}$ & "Apple" \\
\hline $\begin{array}{l}\text { Reducing the operational } \\
\text { logistics costs }\end{array}$ & Optimization of operating costs associated with the logistics activities & "Magnit" \\
\hline $\begin{array}{l}\text { Effective working capital } \\
\text { management }\end{array}$ & Minimization of stock in the distribution network & "Technosila" \\
\hline $\begin{array}{l}\text { Minimizing investments in the } \\
\text { logistics infrastructure }\end{array}$ & $\begin{array}{l}\text { Availability of the minimum allowable number of warehouse } \\
\text { infrastructure facilities that provides the required order cycle time }\end{array}$ & "PepsiCo" \\
\hline Optimizing the service costs & Achieving the minimum level of costs for the customer service & "Swatch" \\
\hline
\end{tabular}

Accounting for the various strategic objectives of distribution logistics and industry-specific features of the enterprise requires the application of systematic approach to the rational distribution network design, i.e. such network that the most closely meets the requirements of the company's corporate strategy. This article covers the existing approaches to the distribution network design, as well the author proposed approach based on a project management methodology.

\section{Literature Review}

A lot of scientific publications are devoted to the logistic networks design. According to some estimates, more than 15-20 articles on the above topic are published annually in the leading international journals (Melo et al., 2009). Such popularity is due to the fact that the task of designing the company's distribution network is purely practical and unique in each case (sectoral specifics, complexity and scale of business, initial assumptions and limitations), and has a tangible impact on the logistics performance indicators. It is no coincidence that over the past few years, the famous Franz Adelman Award for the special achievements in the field of economic benefits approaching through the use of transactions investigation methods in the corporate sector goes to the organizations that have successfully applied the tools of logistics networks design as part of their own distribution network reorganization.

Frequency and international nature of the publications on the topic under consideration have also a negative side: in the specified scientific area, there is no common "language" and, basically, the approach to design. Various authors use the different terms to denote those tasks and problems that they consider in their works. Thus, Cooper (1963) suggests the term "Location-Allocation Problem" (designation of a specific class of tasks within the Facility Location Theory), Drexle (Domschke and Drexl, 1990) "Standort-Einzugsbereich-Problem", Brandeau and Chiu (1989) - "Weber Problem" (by the name of Alfred Weber, the first man, who in 1909 represented the problem of warehouse location for servicing the company's customers on the plane). There are also other titles: "Warehouse Location Problem" (in two versions - "Capacitated" and "Uncapacitated"), "Multi-depot Location Problem", and "SCND Problem". 
However, the essence of most discussed terms is common, and their meanings are often equivalent to one another. For the purposes of this article, we will use the most general variant - "Facility Location Problem".

Most of the works issued by the American and European authors, which are published on the topic of distribution networks design, are devoted to the mathematical side of problem, the model development and the choice of method for solving the task of a certain organization - are considered to both, traditional commercial (oriented to maximize the profits) and non-commercial organizations (for example, hospitals or Educational centres). The wide range of methods for solving such problems, formed to date, is available due to the fact that the problem of facility location and customers distribution (stores, sales regions) between them - NP - is hard, and complexity of its solving, taking into account the increasing number of objects in the distribution network, increases exponentially. In order to estimate the number of operations to be performed by the "solver" (a software package designed to solve problems of linear and nonlinear programming), in obtaining a solution to this problem, the Stirling number of the second kind is used, which is calculated by the formula:

$S(n, m)=\frac{1}{m !} \sum_{k=0}^{m}\left(\begin{array}{c}m \\ k\end{array}\right)(-1)^{k} *(m-k)^{n}$,

where: $\mathrm{n}$ - is the number of customers (stores), $\mathrm{m}$ - is the number of warehouses (options for location).

So, when there are 96 clients and 21 warehouses, the number of possible combinations of the customers "assignment" for the warehouses is expressed as a number of 107 degrees. That is why quite often to solve the problems with real data (for example, for companies of retail chains, which number of stores is measured in thousands), the so-called heuristic and meta-heuristic methods aimed at finding a solution, that is approximate to the optimal, are used.

Reviews of the publications on the topic of distribution networks design are given in the works issued by such authors as Brandeau and Chiu, Daskin (2013), Ambrosino and Skutella (2005), Sahina and Suralb (2007), Melo (Melo et al., 2009; one of the most complete and profound reviews of scientific articles for the recent years). Below we provide the classification of logistics networks design models that is based on the study of both, the above reviews and articles - primary sources (Fig. 1). The GOWAmodel, which assumes the possibility of quickly determining the required number of warehouses close to the optimal one, for servicing the customers in a certain region of goods supply, the demand distribution is set by some function described in the works issued by the American researcher Donald Erlenkotter (1989). The detailed description of models with the continuous facility location on the plane (Models with Exact Demand Distribution) is given in the article by Mark Daskin (2008), and a detailed review of various models with mixed integer programming - in the work by Andreas Klose and Andreas Drexl (2005).

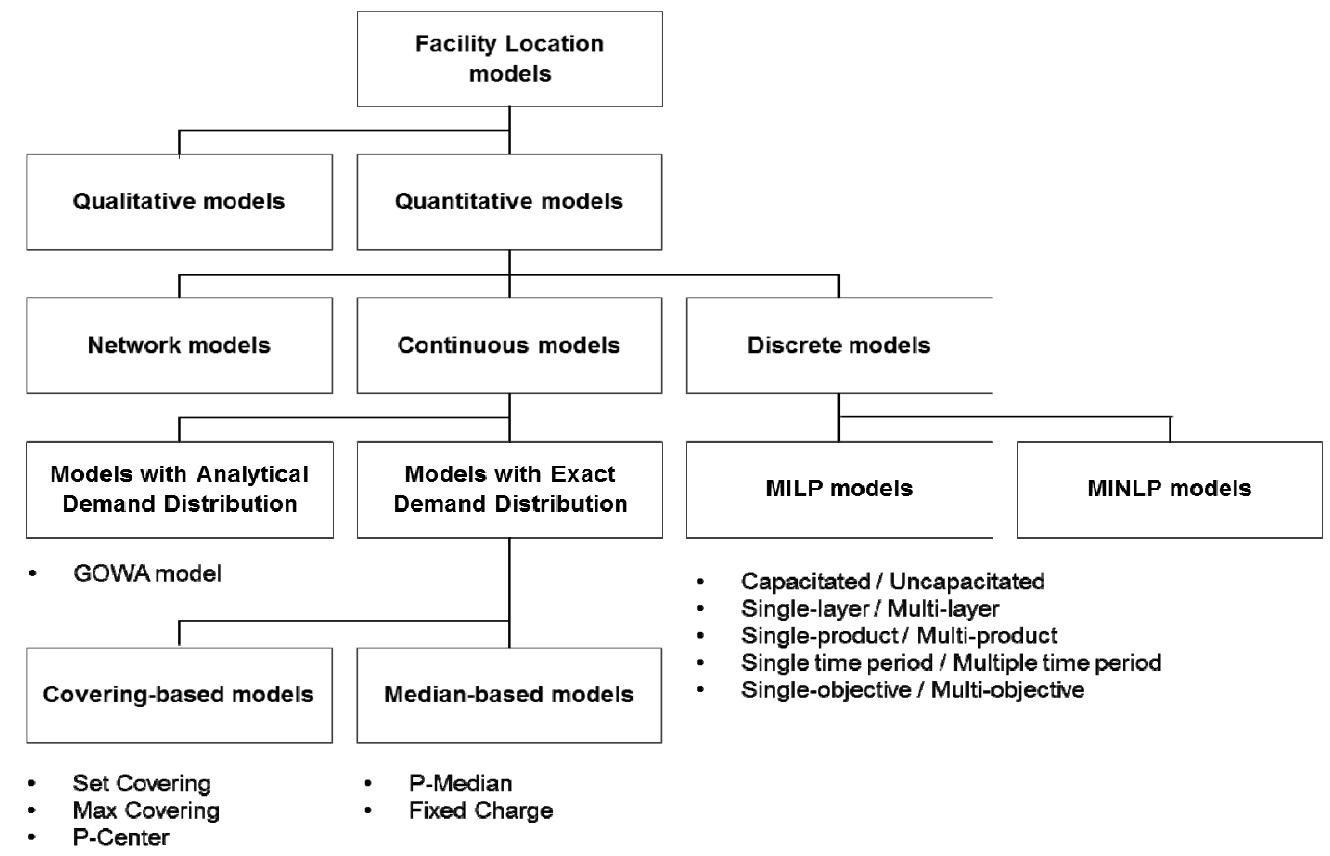

Figure 1. Classification of the Facility Location models 
The methods that are used to solve the problem of network design are also different, and their application in each specific case depends, as already said, on a number of terms: a computational complexity, the required accuracy of solution, available computer powers (solver) for analysis, and the volume of information available. Some methods with references to the relevant authors are given in Table 3.

Table 3. Methods for solving problems on the Facility Location models

\begin{tabular}{|c|c|}
\hline Exact methods & Heuristic and Meta-heuristic methods \\
\hline 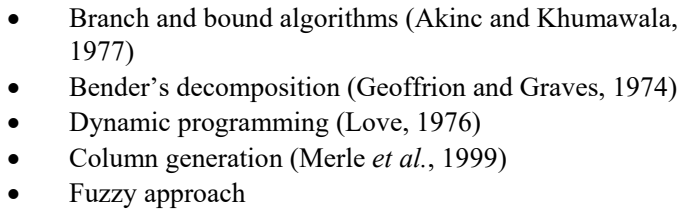 & $\begin{array}{ll}\text { - } & \text { Genetic algorithm (Altiparmak et al., 2006) } \\
\text { - } & \text { Simulated annealing (Jayaraman and Ross, 2003) } \\
\text { - } & \text { Tabu search (Melo et al., 2012) } \\
\text { - } & \text { Variable Neighbourhood search (Bassou et al., 2016) } \\
\text { Kohonen maps (Lozano et al., 1998) }\end{array}$ \\
\hline
\end{tabular}

Analyzing the approaches (algorithms) to the distribution networks design, which are examined in the above-mentioned scientific publications, it should be emphasized that here the approach (algorithm) means the final sequence of project implementation stages for logistic network design (reorganization), assuming the certain terms, the list of operations and those responsible for their performance .

The review of works issued by the above authors on the subject of general logic and actions sequence to implement the distribution network design in the examples of specific organizations allows us to identify four common stages (Fig. 2):

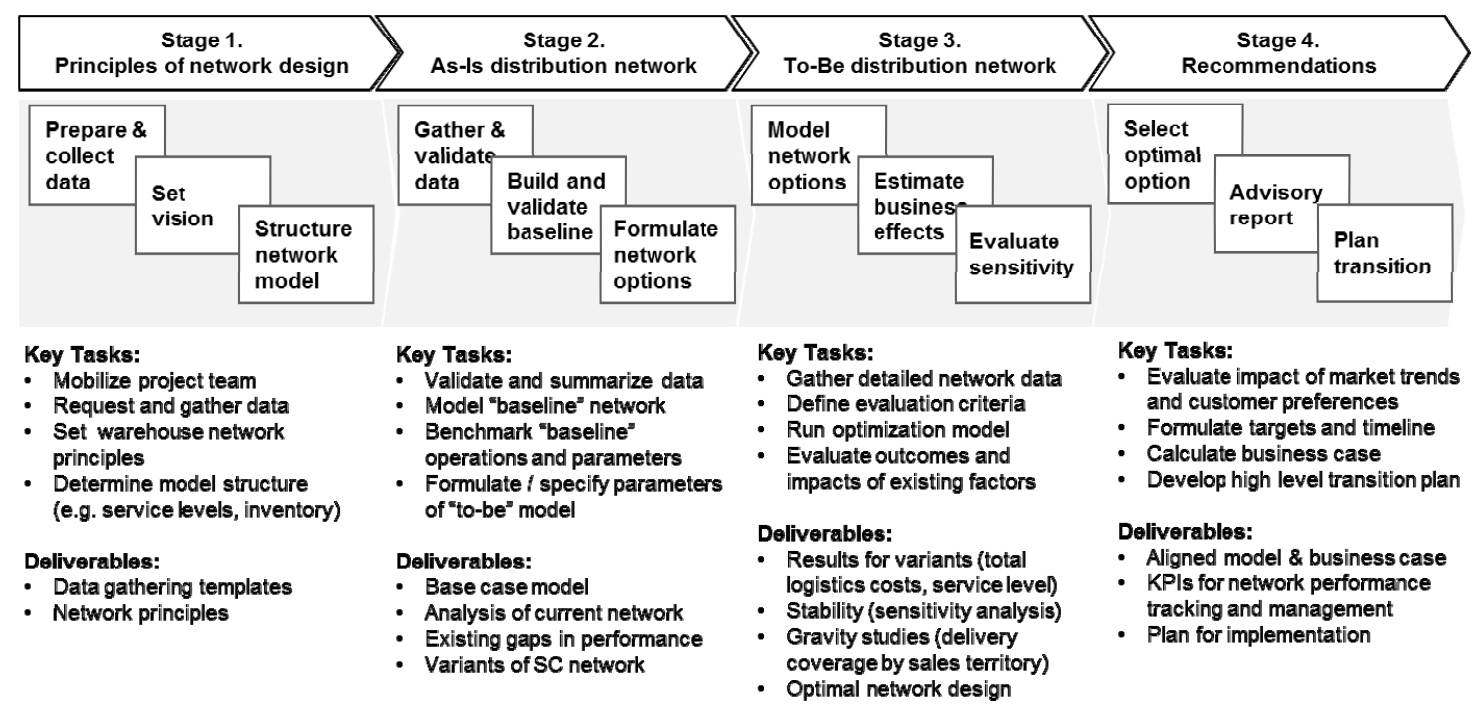

Figure 2. Approach to the network design (by American and European researchers)

1. Defining the model structure and the principles of network design.

2. Analysis of the existing distribution network (data collection and analysis, "as is" modelling of the distribution network, comparison of the model parameters to the actual and target performance indicators, deviations determination).

3. Modelling the target distribution network configuration option (optimization of the existing network model under current conditions, development and modelling of the development scenarios, selection of the optimal network configuration, taking into account the probability of their implementation, analysis of the model sensitivity to the changes in external factors).

4. Preparation of recommendations on the changes implementation.

The above approach includes the main stages of projects on modelling the logistic networks considered in the works issued by the European and American researchers. At the same time, it is worth noting that the main stages outlined in this approach are formulated in the general terms. This means that on the one hand, this approach can be considered as universal for application to the organizations of various industries and activities, but on the other hand, its use is associated with a number of limitations. 
The said approach does not contain the specific explanations and steps for analyzing the company itself, its corporate and logistics strategies, segmentation of the sales network and other factors that determine the optimal configuration of distribution network for the modern enterprise.

The problem of approach development to design the distribution network was studied by the following Russian authors: V.V. Dybskaya (Dybskaya and Sverchkov, 2015), V.S. Lukinsky (Lukinskiy et al., 2002), B.A. Anikin (2010), Yu.M. Nerush (2006).

Upon review of the main approaches to the network design, they can draw the following conclusion: each approach has its advantages and disadvantages in comparison with others. Moreover, each approach proposed by the domestic authors focuses on one or more of several problems within the overall task of optimal network design. For example, it may relate to the establishment of ties with the corporate strategy, the customer base segmentation, solving the tactical problems of planning in the transport network, allocation of the sales areas or mathematical techniques of the warehouse network modelling. However, none of these approaches individually covers the full range of problems on the rational distribution network formation. In this context, the problem of such approach development which would cover both the strategic aspects (interrelation of objectives and requirements for the distribution network and the company strategy as a whole and specifically logistic strategy), and practical aspects, which are related to the optimization of costs and the level of logistical service at the consumer service, becomes relevant.

\section{Methodology}

The logistic distribution system is a combination of logistics distribution network and management system, which is formed by the company to implement its own logistics strategy (Dybskaya et al., 2008). In turn, the logistics distribution network should be considered as a set of links of the logistics system (LS), including a set of physical objects, the interconnection between which is established though the main and associated flows. From this we can conclude that the optimal LS development falls completely under the concept of project, and to design it, the methodology of project management can be taken as a basis (Shapiro and Mazur, 2001).

Considering the distribution network as part of a complex logistics system, when designing it, it is advisable to use the methodology of complex systems design. In this case, the distribution network project, like any other system, can be analysed in two ways: as a structure and as a process.

Structural basis of the distribution network design will be its elements. Thus, the project can be divided into the elements in different ways, so they can talk about different approaches to the design decomposition. The decomposition may be performed with varying degrees of detail, depending on the accepted division level, in one case, it can be the supply chains, in other cases it can be the links of logistics system or even its elements - subjects of the logistics infrastructure. In our case, the following can act as the network distribution elements: storage facilities (at the level of the warehouse network and a specific warehouse with its infrastructure), transport facilities, information system, etc.

The design procedure as part of the project implementation for the optimal logistics network formation provides usually the development of several competitive options for the logistics distribution system. Implementation of the procedure for existing network design or reorganization is the most complex issue in the Project implementation. The procedure implementation is based on the goals and objectives defined by the logistics strategy, which is developed under the corporate and functional (marketing, production, etc.) company strategies. Namely the logistics strategy is the starting point in determining the global and local goals and objectives facing the designed distribution network. Their achievement allows you to determine the key criteria for optimizing the network functioning, to identify a range of restrictions related to the customers' requirements, the company's capabilities and competitive environment in the sales market. The logistics strategy facing the company becomes the basis for the distribution network design and its logistics infrastructure.

The reorganization procedure is a particular task in the network designing issue and differs in that it requires a preliminary analysis of already existing distribution network, in the context of possible fulfilment of newly set goals and tasks.

Conditionally, the procedure for rational logistics distribution network design or reorganization consists of the following three stages (Fig. 3). 


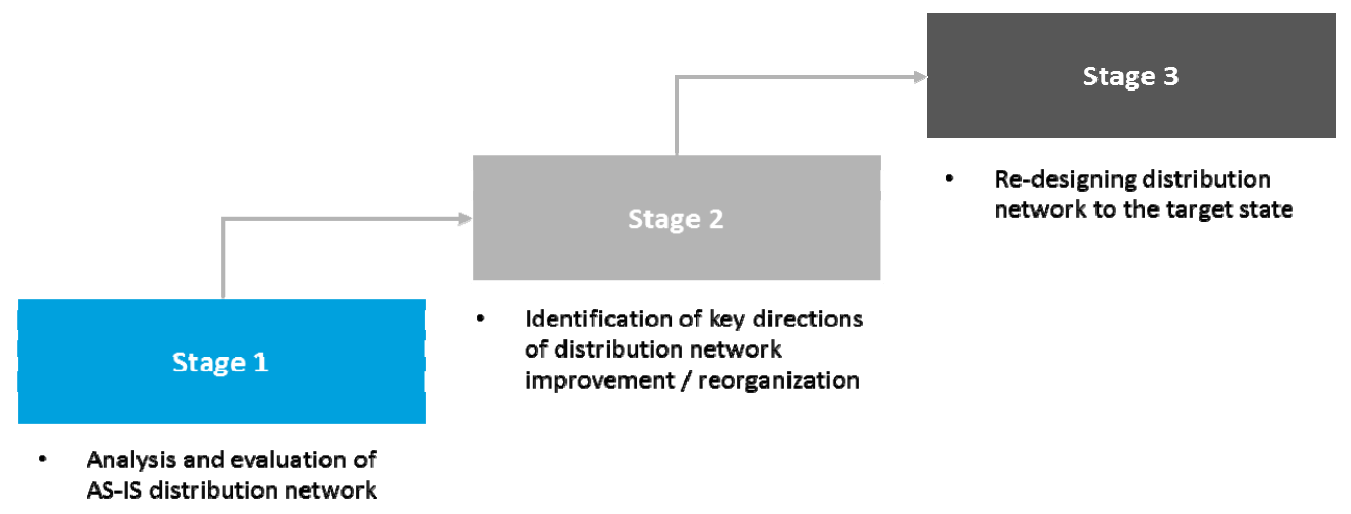

Figure 3. Procedure for rational distribution network design

\subsection{Stage 1. Analysis and evaluation of the existing logistics distribution network functioning (analysis of problems, identification of the main causes or factors that have affected the distribution network efficiency)}

Within this stage, the main causes or problems that have affected the decrease in the distribution system efficiency are identified. After carrying out the analysis and establishing the causes, the necessity of distribution network reorganization is determined and the terms of reference for the distribution network design is prepared. The existing distribution network of any company depends on the external conditions that occur in the market and the changing internal environment. These changes can significantly affect the network performance indicators. That is why the company's logistics service should ensure the regular (with a certain periodicity) control over the established indicators that assess the distribution network activities. In the event of deviations from the specified efficiency criteria and reducing their magnitude, an evaluation of existing distribution system and an analysis of causes that led to such changes shall be provided.

Initially, it is necessary to determine the technique and methods for carrying out the analysis, to identify conditions for the project implementation, the sources for obtaining information to generate the initial data, and the procedure for collecting them. When assessing the effectiveness of current distribution system, the analysis of business processes carried out when promoting the commodity flows through the existing distribution network is often used.

The evaluation procedure shall include: conducting an analysis, in accordance with the developed methodology, developing a research scheme, evaluating the main indicators of network efficiency, including the logistics costs. If the assessment of causes that led to a decrease in efficiency confirms the impossibility of existing network to meet the set goals, a decision shall be made on the need for its reorganization.

To implement Stage 1, the following procedure is proposed:

1.1 Identification of the goals and objectives for the logistics distribution network in accordance with the existing company's logistics strategy.

The system objectives and tasks facing the distribution network are determined, in accordance with the logistics strategy approved by the company. The objectives to be set should be result-oriented and have the quantitative or qualitative assessment to determine the extent to which they are achieved.

1.2 Definition of the general conditions of existing distribution network functioning (taking into account the external environment of business, the existing structure of consumer demand and service requirements, and the company's existing logistics infrastructure).

1.3 The main approaches to the system analysis and evaluation assume:

- Analysis of the actual possibilities to examine the system activities on its own

- Evaluation of the own resources for analysis

- Selection of the performers (from among its own employees, or with the involvement of consulting firms), and

- Development of the analysis and evaluation methods.

In those cases, where the organization decides to independently analyse and evaluate the distribution system functioning, this procedure is carried out according to the following scenario.

1.4 Analysis and evaluation of the existing distribution system:

1.4.1 Determine the analysis technique and methods. 
1.4.2 Analysis of the existing structure of logistics network and the organizational structure of company distribution management;

- Analysis of the efficiency of the main logistics functions performed by the company departments and divisions within the distribution system

- Analysis of the satisfaction degree of internal consumers and external customers of the company with the quality of logistics service within the distribution system

- Analysis of the rationality degree in the use of financial, material and labour resources in the performance of distribution functions

- Analysis of the total costs for distribution logistics and logistics costs components by type of activities

- Analysis of the presence of conflict situations between the company's subdivisions by logistic parameters and cross-functions in the management of logistics processes within the distribution system

- Analysis of the workflow efficiency and data exchange, relating to the problem solving matter in the distribution system, within the company structural divisions and customers

- Analysis of the stock concentration in the warehouses of distribution network

- Analysis of the needs status and planning, and the inventory management

- Analysis of the warehouse facilities, transport and other logistics infrastructural units in the distribution.

1.4.3 Evaluation of the need to reorganize the logistics distribution network:

- Evaluation of the distribution network functioning and the activities of organizational structure of the management, on the basis of analysis conducted

- Identification of the problems that have changed the distribution network efficiency

- Analysis of the causes (external and internal) that affected the changes in the system activity (decrease in efficiency)

- Determination of the need to reorganize the logistics system.

According to the materials obtained as a result of analysis, an evaluation of possibility to achieve the set goals within the existing distribution network or the need to reorganize the logistics distribution network shall be carried out. For this purpose, the obtained performance indicators of the logistics distribution network shall be evaluated, in accordance with the established efficiency criteria. Their deviations and causes, which have led to change in the logistical distribution network efficiency, shall be defined. Based on the analysis of causes (external and internal) that affected the changes in the system performance (decrease in efficiency) and evaluation of the existing distribution network efficiency, the following decisions shall be made:

- To eliminate the existing causes that reduce the distribution network efficiency, by improving the organization of processes used without the existing distribution network reorganization, or

- $\quad$ To reorganize the existing distribution network.

In those cases, when a decision related to the need to reorganize the distribution network is made, at Stage 2 the logistics service shall prepare the key requirements for the basic design of distribution network (feasibility study).

\subsection{Stage 2. Identification of key directions of the logistics distribution network reorganization on the basis of existing distribution system efficiency analysis and evaluation (preparation of requirements for the basic design, initial data collection and their analysis to develop the options of design solutions)}

Analysis and collection of initial data for the development of design solutions options for the distribution network are carried out. The development of terms of reference to the basic design of logistics distribution system is provided. The need for changes in the existing logistics distribution network efficiency identified on the basis of the analysis and evaluation requires the identification of key directions of its reorganization that ensure the fulfilment of the company's strategic goals. To implement the design and collection of necessary information, a team group shall be formed at the head of the logistics service. 
The team group can be formed from the contractors of the company itself, which provides the network reorganization, or it can be represented by a team of any consulting company involved for this purpose. At the same time, it is not excluded that the execution of tasks can be divided among different team groups, for example, the collection and analysis of initial data can be performed by a group of contractors assigned by the customer, and the design of options can be performed by the team of consulting company. However, the evaluation of proposed options for design solutions and the choice of their rational item shall be carried out by the customer's company team.

When designing the distribution network and determining the global and local goals and tasks facing it, it is necessary to proceed from the corporate interests of company, the accepted strategy for its development, and also take into account the functional strategies of company's related services and, in the first place, the marketing strategy and logistics strategy.

An obligatory condition for determining the system tasks and set goals is measurability, which allows you to objectively evaluate the results of their implementation in the future. Specific values are also set, when determining the efficiency criteria for each local network and the entire distribution system. The necessity to determine the quantitative value of set efficiency criteria greatly facilitates the evaluation process and gives a more adequate characterization of the analysed system.

In order to maintain the effectiveness of logistics distribution network, when evaluating its performance indicators and the ability to achieve the set tasks, the company should determine not only the need to reorganize the distribution network, but also its direction adequately the occurred situation.

The design development (its implementation) at this stage will include: the selection of project team, the definition of project structure, the work schedule drawing, the development of competitive options, the identification of necessary costs and resources, the preparation of all necessary documentation. When developing a basic design aimed at the distribution network reorganization, the designers shall prepare several competitive options of the design solutions. Those of them that fit into the level of necessary restrictions and in the range of set indicators will be recognized as competitive. It is these options in the future will be considered by the experts, when choosing the most rational option. The analysis and evaluation of proposed solutions should include: analysis of the alternatives, sensitivity analysis, analysis to identify the best system to evaluate the logistics costs and efficiency of each option, and risk assessment.

Implementation of the second stage involves the following procedure:

2.1 Definition of the system goals (global and local) based on the logistics strategy approved by the company and the tasks facing the distribution system.

The proposed goals and objectives should be results-oriented and have a quantitative or qualitative assessment to determine the extent to which they have been achieved. When choosing the distribution strategies that meet the interests of proposed logistics strategy, it is necessary to take into account a number of main factors, influencing the decision making process, on the part of logistics:

- Existing logistics infrastructure of the company and its potentials focused on the implementation of goals set for the distribution network

- Analysis of the demand for logistics services on the part of customers and requirements imposed by the consumers for the logistics service, and compliance with the existing distribution network

- Analysis of the competitive environment from the perspective of logistics services implementation (list of the services provided and their tariff scale)

- Geography of the customer base and the main types of consumers in view of the supply frequency, requirements for the order provision (assortment list and lot size), and

- Offers of the logistics services market that provide the possibility of rational choice for the "insourcing-outsourcing", etc.

2.2 Identification of restrictions imposed on the activities of distribution system as a whole.

Restrictions most often concern the conditions of logistics infrastructure functioning, and are connected usually with the investment resources. Restrictions may include other resources and opportunities of the company: labour, technical, information, etc.

2.3 Identification of the KPI's and efficiency criteria for the designed distribution system.

Criteria for the distribution system efficiency should be based on the goals and objectives, as well the requirements of customers to their service. Key indicators shall cover the assessment of costs associated with the distribution network functioning, the use of existing assets, the fulfilment of customers' requirement for the orders provision, etc. 
2.4 Analysis of the available resources capabilities within the existing distribution system in order to achieve the set criteria optimization (by improving the process organization, performance, and other potentials, which do not affect the fundamental changes in the existing network).

2.5 Identification of the possible key directions of distribution network reorganization, which ensure its efficiency.

The efficiency of distribution network can be related to improving the service level, reducing the costs (one-time) or eliminating the unnecessary costs (reducing variable costs), reducing the order cycle time, increasing the productivity of logistics infrastructure, by using the modern process solutions and the introduction of information systems. The change in these indicators may cause the distribution network reorganization and identification of the reorganization direction.

The reorganization process may cover a variety of levels: from the design of new distribution network, with the exclusion (sale) of existing elements of the logistics infrastructure, or, conversely, the inclusion of additional elements (for example, one or more existing warehouses), before changes in the goods flow techniques in the certain supply chains. In practice, the reorganization process is most often associated with changes in the logistics infrastructure, for example, the expansion of warehouse network, the use of new technologies for goods circulation, the introduction of modern information system that provides a single information space at the whole company level, covering the entire warehouse facilities at the macro level, etc.

2.6 Development of the detailed project (process) report for the logistics distribution network reorganization (basic version).

The detailed project report applies to those directions of the distribution network reorganization, which will allow you achieving the goals set for it. The most complete option will concern the design of optimal option of the logistics distribution network. The detailed project report is submitted to the team group of designers.

As a result of Stage 2 implementation, the terms of reference shall be prepared for the basic design of distribution network, taking into account the selected directions of reorganization. The very procedure of distribution network design is usually carried out by the designers - representatives of the consulting companies.

\subsection{Stage 3. Reorganization or design of the optimal logistic distribution network (selection of the optimal option for the design solutions and detailed design). Development of the project implementation plan}

The developers prepare several basic options of the design solutions, in accordance with the received terms of reference. Selection of the optimal option for the designed distribution network is carried out by the customer's experts (an independent expert or a Logistics Director and his team). The selection is made on the basis of analysis provided by the developers and evaluation of each competitive option for the design solutions, where the indicators of design solutions evaluation, optimality (or rationality) criteria are given, and a system of risk assessment and planning responses to possible (most frequently occurring) changes are provided. Based on the results of selection (by the company's representatives) the designers provide some certain recommendations for the approved option to implement the project. At the end of stage, a project implementation plan shall be issued, including an implementation plan, a measures schedule to implement and determine the indicators and possible deviations in the results of implementation

Procedure for Stage 3 implementation involves the following sequence:

3.1 Harmonization and approval of requirements for the designed distribution network.

3.2 Approval of the goals and objectives to optimize the distribution network based on agreed logistics development strategy.

3.3 Determination of the planned sales volume by the market regions.

Determination of the demand forecasting procedures, with a strategic focus on the forecast level, and potential sales markets shall be provided by the marketing service department. However, the Project Developers shall monitor the fulfilment of forecast, since a possible error can lead to the disastrous consequences, especially when developing the logistics infrastructure and specific warehouses, as its main elements. Based on the forecast, the volumes of planned sales and the types of potential customer base shall be determined for the potential sales regions.

3.4 Sales regions segmentation and Goods supply regions identification. 
The sales regions segmentation, which is carried out by the marketing department, allows the logistics to combine a number of geographically close to each other sales markets into the goods supply regions. The entire region of goods supply is served by one regional warehouse, at the same time, each of its incoming sales region can have the affiliated warehouses (sub-sorting), which ensure the reduction of order cycle. When forming the goods supply regions, the main optimization criteria shall be the minimization of transportation costs, when servicing customers at the given time of order execution.

The potential sales regions, which are allocated by marketing, are combined by the logistics into the specific segments-supply hubs to create the regional warehouses of storage network, from where the customer service will be provided. Determination of the inventory level (in days) for the main types of customers by sales regions, and determination of the delivery frequency (in days, based on the experience of servicing this type of customers). It is these indicators that are further determining, when calculating the necessary capacity and are of the warehouse, from where the goods will be supplied to the customers.

3.5 Calculating the cargo flows in the distribution network by sales regions and goods supply regions.

Calculation of the freight flows (indicative) is based on the obtained data on planned sales volumes (usually, the turnover value), the average level of commodity stocks (in days) by regions, depending on the needs of customers for deliveries.

The company shall provide the customer service policy, which form a set of logistics services provided and identify the basic standards for their implementation. The developed service policy should be uniform for the entire distribution network, the basic standards for services should be unified too, but the level of their provision, not only for each customer, but also for a specific sales region, may be differ. This is dictated by the fact that the costs for the provision of logistics services are heavily dependent on certain factors, and the prioritize maintenance requirements can be very different for each region. At the strategic level, when designing the distribution network, the best indicator, on which you can focus on at the customer service, is the order execution time and minimum logistics costs.

3.6 Selection of models and methods for solving problems within the distribution network design. Formalization of the goals and constraints for the designed distribution network.

To design the distribution network, taking into account the logistics features of the sales regions and with reference to the selected regions of goods supply, those models and methods are selected that ensure the achievement of optimization criteria at different levels of strategic problems solving (formation of the goods supply regions, region determination for the regional warehouses construction, etc.).

3.7 Logistics infrastructure development for the distribution network.

3.7.1 Allocating the local supply chains in the distribution network by sales region and taking into account the customer base.

Local supply chains, depending on the distribution network configuration, can be focused on all the supply chain elements, which are involved in the promotion of commodity flows, from the central warehouse to the specific customers in the sale region. In case of the considerable branching of distribution network and the level of problem solution, the supply chain can be reviewed starting from the regional warehouse to the specific consumers. The common distribution network is the combination of its supply chains. The main condition is that, when choosing the principle of supply chain allocation and their optimization, you shall proceed from the provision of objective function and optimization constraints of the entire distribution network, as determining for each supply chain.

3.7.2 Warehouse network development within the designed distribution network.

In each sales region, depending on the type of customers, the frequency of delivery and cargo traffic, the warehouse functionality shall be selected. The calculation of warehouses number and the selection of their functional purpose shall be practically carried out simultaneously with the determination of warehouse location (within the region of goods supply). The designers shall offer several options for the warehouses network that form the distribution network. For the proposed options of warehouses location, based on the analysis of logistics services market and the proposed rental storage facilities, the form of ownership shall be selected for the proposed warehouses. After that, the system of goods supply within the forming warehouse network shall be determined.

The developed warehouse network configuration, with drawing each prospective warehouse on a place map, will be the distribution network basis.

3.7.3 Choosing the technologies for goods delivery to provide a unified Process Policy.

For the designed distribution network, depending on the branching of warehouse network and the functional purpose of warehouses, the delivery technologies are developed within each selected supply 
chain. In the presence of all three options (by functional purpose: distribution, distribution and sorting, and sorting), the technologies shall be selected from warehouse to warehouse and from warehouse to customer.

The step assumes:

- Choosing the optimal type of goods medium

- Choosing the vehicle for delivery

- Development of the optimal delivery routes to customers.

Determination of the goods medium shall be done for each supply chain: from each supplier to the consumer. The choice shall be made by taking into account the customer location, the applicable form of sale at the end user, the delivery lot (by assortment and size), the frequency of delivery, the type of consumer packaging and packaging dimensions, transport packaging and containers, goods storage conditions, and temperature conditions.

When choosing the vehicles on each segment of the supply chain (from link to link), it is necessary to take into account the following: selected type of the goods medium, size of the delivery lot, the distance range (mileage), the geography of consumers, the availability of handling ramp and technical means at the customers' site, the storage conditions of goods during transportation. The choice of vehicle shall ensure its maximum use by the normative carrying capacity or cargo capacity.

3.7.4 Providing a single information space in the distribution network:

- Preparing a single information system for all the supply chains

- Workflow management for all participants in the supply chain

3.8 Choosing the optimal option for the logistics distribution network.

3.8.1 The establishment of restrictions (measured) imposed on the activities of distribution network, in compliance with the statutory requirements and taking into account the proposals for the logistics infrastructure development.

3.8.2 The competitive options development for the logistics distribution network, as a set of supply chains.

3.8.3 Determination of the key indicators value for each option and their comparison with the set criteria for estimating the distribution network.

For a more complete evaluation of developed distribution network options, it is advisable to use the integrated LDS estimation system, with the maximum number of indicators. Final evaluation often involves a number of complex indicators:

- Evaluation of the logistics infrastructure efficiency aimed at the implementation of goals and objectives related to the customer service

- Degree of the customer satisfaction with the services provided by the supplier

- Degree of the supplier's response to changes in the customer demand

- Level of the logistics costs associated with the distribution network operation

- Level of the inventory concentration within the distribution network.

Sometimes, the company considers it appropriate to confine the key indicators only.

3.8.4 Evaluation of the activities of the developed logistics distribution network options.

3.8.5 Choosing the optimal distribution network option.

3.9 Determination of costs associated with the implementation of optimal network option.

When assessing the designed option of distribution network, an indicator of total costs associated with the implementation of a particular option, which is calculated as the sum of the one-time costs for the implementation of design itself and the operation of designed logistic distribution network, can be used. The major non-recurring investments include the costs associated with the development of logistics infrastructure for:

- Warehouse network: design and construction of all the storage facilities of the warehouse network, their technical equipment, as well as their storage infrastructure

- Transport facilities: purchase of the necessary number of rolling stock and transport fleet infrastructure

- Information system: computers, network equipment, and software.

The total costs associated with the logistics distribution network functioning include not only the logistical costs, but also part of the costs that are not directly associated with the logistics activities of the company. In those cases, where the company resorts to the services of logistics providers, the cost value includes all the costs associated with the payment of logistics services.

When calculating the logistics costs of distribution network, it is expedient to calculate each supply chain that is a part of general logistics distribution system. 
3.10 Development of a plan for implementing the proposed solution to design (or reorganize) the distribution network.

3.11 Monitoring and control organization over the activities of designed logistics distribution network.

\section{Conclusion}

Procedure for a rational distribution network design, which is proposed within this article, allows you to make decisions on the target configuration of a logistics network that meets the company's strategic goals. At the same time, it takes into account the peculiarities of corporate strategy at the goods supply level in the individual regions, product categories, and customers' (stores) segments. However, taking the said features into account does not mean the separate network design for each of the local supply chains; on the contrary, it allows you to clarify the logistics requirements for each chain, but within a single distribution network and common warehouse facilities used to serve different customer segments or trade formats. In this way, according to the authors of this work, the rationality of distribution network is achieved - its most complete correspondence to the company development strategy.

\section{Acknowledgement}

This article is an output of a research project "Investigation of the main directions of development of logistics companies in the context of adapting to the changing economic reality in Russia", implemented as part of the Research Program of the Faculty of Business and Management at National Research University - Higher School of Economics.

\section{References}

1. Akinc, U., Khumawala, B.M. (1977) An Efficient Branch and Bound Algorithm for the Capacitated Warehouse Location Problem. Management Science, Vol. 23, Issue 6, pp. 585-594

2. Altiparmak, F., Gen, M., Lin L., Paksoy, T. (2006) A genetic algorithm approach for multi-objective optimization of supply chain networks. Computers \& Industrial Engineering, Vol. 51, pp. 196-215

3. Ambrosino, D., Scutella M.G. (2005) Distribution network design: New problems and related models. European Journal of Operational Research, Vol. 165, pp. 610-624

4. Anikin, B.A. (2010) Logistics. Moscow: Infra-M.

5. Bassou, A.A., Hlyal, M., Alami J.E. (2016) Stores Location Model For Distribution Network Design: An Effective Variable neighbourhood Search Approach for a Two Level Capacitated Location Allocation Problem. Journal of Applied Sciences, Vol. 16, Issue 2, pp. 37-46

6. Brandeau, M.L., Chiu, S.S. (1989) An overview of representative problems in location research. Management Science, Vol. 35, Issue 6, pp. 645-674

7. Cooper, L. (1963) Location-Allocation Problems. Operations Research, Vol. 11. Issue 3, pp. 331-343

8. Daskin, M.S. (2008) What You Should Know About Location Modelling. Naval Research Logistics, Vol. 55, pp. 283-294

9. Daskin, M.S. (2013) Network and Discrete Location: Models, Algorithms and Applications. 2nd Edition. New York: John Wiley \& Sons, Inc.

10. Domschke, W., Drexl, A. (1990) Logistik: Standorte. 3 Auflage, München: Springer.

11. Dybskaya, V.V. (2012) Basic approach to design and reorganization of a distribution network. Logistics and Supply Chain Management, Vol. 51 (4), pp. 9-15

12. Dybskaya, V.V., Sverchkov, P.A. (2015) Approach to design a rational distribution network of a retail company. Logistics and Supply Chain Management, Vol. 66 (1), pp. 44-59

13. Dybskaya, V.V., Zaytsev E.I., Sergeev V.I., Sterligova, A.N. (2008) Logistics. Integration and optimization of logistic business processes in supply chains: manual for MBA students. Moscow: Eksmo.

14. Erlenkotter, D. (1989) The general optimal market area model. Annals of Operations Research, Vol. 18, Issue №1, pp. 43-70

15. Geoffrion, A.M., Graves, G.V. (1974) Multicommodity Distribution System Design by Benders Decomposition. Management Science, Vol. 20, Issue 5, pp. 822-844

16. Jayaraman, V., Ross, A. (2003) A simulated annealing methodology to distribution network design and management. European Journal of Operational Research, Vol. 144, pp. 629-645 
17. Klose, A., Drexl, A. (2005) Facility location models for distribution system design. European Journal of Operational Research, Vol. 162, pp. 4-29

18. Love, R.F. (1976) One-Dimensional Facility Location-Allocation Using Dynamic Programming. Management Science, Vol. 22, Issue 5, pp. 614-617

19. Lozano, S., Guerrero, F., Onieva, L., Larraneta, J. (1998) Kohonen maps for solving to a class of location-allocation problems. European Journal of Operational Research, Vol. 108, pp. 106-117

20. Lukinskiy, V.S., Bochkarev, A.A., Pekhovskiy O.Y., Tsvirynko, I.A. (2002) Evaluation of an impact of warehouse network design to transportation costs. Economics and Management in Transportation, Vol. 2, pp. 88-96

21. Melo, M.T., Nickel, S., Saldanha-da-Gama, F. (2009) Facility location and supply chain management - A review. European Journal of Operational Research, Vol. 196, pp. 401-412

22. Melo, M.T., Nickel, S., Saldanha-da-Gama, F. (2012) A tabu search heuristic for redesigning a multiechelon supply chain network over a planning horizon. Int. J. Production Economics, Vol. 136, pp. 218-230

23. Merle, O., Villeneuve, D., Desrosiers, J., Hansen, P. (1999) Stabilized column generation. Discrete Mathematics, Vol. 194, Issues 1-3, pp. 229-237

24. Nerush, Y.M. (2006) Logistics. 4th Edition. Moscow: Prospect.

25. Sahina, G., Süralb, H. (2007) A review of hierarchical facility location models. Computers \& Operations Research, Vol. 34, pp. 2310-2331

26. Shapiro, V.D., Mazur, I.I. (2001) Project management. Moscow: Higher School. 